\title{
CORRESPONDENCE Expanding the definition of pediatric environmental health
}

\author{
Pediatric Research (2020) 87:976; https://doi.org/10.1038/s41390- \\ 019-0426-4
}

We read with interest the recent call for research articles on environmental health. ${ }^{1}$ This call for papers provides a concise summary of the past accomplishments of pediatric-focused environmental research, as well as developing threats to current and future research and the potential impact on child health. Although environmental health has traditionally focused on identifying and protecting the public from exposure to harmful substances in air, water, soil, and food, ${ }^{2}$ we propose a broader definition that encompasses a more holistic vision of health and the environment. Just as the World Health Organization famously defined health as being "a state of complete physical, mental, and social well-being and not merely the absence of disease or infirmity", ${ }^{3}$ we hope that the new environmental health section in Pediatric Research will focus not only on the health risks of environmental toxins, but also the health benefits of positive environmental exposures. More precisely, we would like to see additional published research regarding the growing list of positive health benefits from exposure to the natural environment.

There is currently accumulating research demonstrating that access to quality green spaces and natural environments decreases stress and enhances a number of health-related outcomes. For example, a simple walk through nature improves affect as well as working memory performance as compared to a walk through an urban environment, ${ }^{4}$ and having contact with nature for at least 10 minutes, three times weekly resulted in decreases in salivary cortisol and alpha-amylase in adults living in an urban environment. ${ }^{5}$ Indeed, the more time adults spend outdoors, the lower their depression scores are. ${ }^{6}$ Such benefits may play an even more prominent role in promoting mental health in children and adolescents. Simply spending time outdoors can help decrease internalized mental health symptoms in girls, ${ }^{7}$ enhance self-discipline in girls growing up in poverty, ${ }^{8}$ and children with high levels of nature exposure are less likely to develop mental illnesses in adulthood. ${ }^{9}$

The benefits of engagement with and exposure to nature are not limited to mental health. In fact, the loss of trees due to the spread of the emerald ash bore resulted in increases in myocardial infarction in women ${ }^{10}$ and in overall cardiovascular mortality. ${ }^{11}$ Consistent with these findings, counties with more shrub and forest land have lower Medicare expenses. Interestingly, land covered in grass (that is, lawns) does not convey this benefit. ${ }^{12}$

The growing body of research examining connections between nature access, outdoor play, and healthy child development is of legitimate, and even urgent, interest to pediatric health care practitioners. Although the field of pediatrics has strongly emphasized the importance of play in child development, ${ }^{13}$ the importance of outdoor play and exposure to nature should be just as prominent. ${ }^{14}$ Much of the nature-related research is published in professional journals outside of typical medical establishment journals, such as in the fields of psychology, environmental studies, urban design, and public health. By including and welcoming this research, we hope to encourage a broader definition of pediatric environmental health, and to promote healthier children, families, schools, and communities.

\section{ADDITIONAL INFORMATION}

Competing interests: The authors declare no competing interests.

Publisher's note: Springer Nature remains neutral with regard to jurisdictional claims in published maps and institutional affiliations.

Terrill Bravender ${ }^{1}$ and Lee Smith Bravender ${ }^{2}$ ${ }^{1}$ Department of Pediatrics, University of Michigan, Ann Arbor, MI, USA and ${ }^{2}$ Matthaei Botanical Gardens and Nichols Arboretum, University of Michigan, Ann Arbor, MI, USA Correspondence: Terrill Bravender (tdbrave@umich.edu)

\section{REFERENCES}

1. Wright, R. O., Bearer, C. F. \& Witherspoon, N. O. Calling for research articles on environmental health. Pediatr. Res. 85, 414 (2019).

2. American Public Health Association. Protecting the health of children: a national snapshot of environmental health services. https://www.apha.org/topics-andissues/environmental-health/child-health (2019).

3. World Health Organization. Preamble to the Constitution of WHO as adopted by the International Health Conference, New York, 19 June-22 July 1946; signed on 22 July 1946 by the representatives of 61 States (Official Records of WHO, no. 2, p. 100) and entered into force on 7 April 1948.

4. Bateman, G. N., Daily, G. C., Levy, B. J. \& Gross, J. J. The benefits of nature experience: improved affect and cognition. Land. Urban Plan. 128, 41-50 (2015).

5. Hunter, M. R., Gillespie, B. W. \& Chen, S. Y.-P. Urban nature experiences reduce stress in the context of daily life based on salivary biomarkers. Front. Psychol. 10, 722 (2019).

6. Beyer, K. M. M., Szabo, A. \& Nattinger, A. B. Time spent outdoors, depressive symptoms, and variation by race and ethnicity. Am. J. Prev. Med. 51, 281-290 (2016).

7. Piccininni, C., Michaelson, V., Janssen, I. \& Pickett, W. Outdoord play and nature connectedness as potential correlates of internalized mental health symptoms among Canadian adolescents. Prev. Med. 112, 168-175 (2018).

8. Taylor, A. F., Kuo, F. E. \& Sullivan, W. C. Views of nature and self-discipline: evidence from inner city children. J. Environ. Psychol. 22, 49-63 (2002).

9. Engemann, K. et al. Residential green space in childhood is associated with lower risk of psychiatric disorders from adolescence into adulthood. Proc. Natl Acad. Sci. USA 116, 5188-5193 (2019).

10. Donovan, G. H., Michael, Y. L., Gatziolis, D., Prestemon, J. P. \& Whitsel, E. A. Is tree loss associated with cardiovascular-disease risk in the Women's Health Initiative? A natural experiment. Health Place. 36, 1-7 (2015).

11. Donovan, G. H. et al. The relationship between trees and human health. Am. J. Prev. Med. 44, 139-145 (2013).

12. Becker, D. A., Browning, M. H. E. M., Kuo, M. \& Van Den Eeden, S. K. Is green land cover associated with less health care spending? Promising findings from county-level Medicare spending in the continental United States. Urban Forest. Urban Green. 41, 39-47 (2019).

13. Yogman, M., Garner, A., Hutchinson, J., Hirsh-Pasek, K. \& Golinkoff, R. M. The power of play: a pediatric role in enhancing development in young children. Pediatrics 142, e20182058 (2018).

14. Mainella, F. P., Agate, J. R. \& Clark, B. S. Outdoor-based play and reconnection to nature: a neglected pathway to positive youth development. New Dir. Youth Dev. 130, 89-104 (2011). 